\title{
Experimental study on the compression characteristics of soft soil based on low temperature effect
}

\author{
Jian Zhang, Chunpeng Han*, Jiayi Tian and Qingjie Dong \\ School of Civil Engineering, Northeast Forestry University, Harbin 150040, China \\ *Corresponding Author : hcp_1979@163.com
}

$\begin{array}{ll}\text { Submitted } & : 23 / 05 / 2019 \\ \text { Revised } & : 06 / 04 / 2020 \\ \text { Accepted } & : 02 / 11 / 2020\end{array}$

\begin{abstract}
Based on the characteristics of long annual freezing time and short suitable construction period of soft soil in cold region, this paper discusses the feasibility of foundation treatment of soft soil in freezing-thawing layer under freezing condition. The deformation characteristics of soft soil in freezing-thawing layer in Hulunbuir area in China are studied by using two compression test methods, namely, constant temperature and variable load (CTVL) test, variable temperature and variable load (VTVL) test. The compressibility indexes under different temperatures and consolidation pressures are obtained. The research shows that the freezing-thawing soft soil has large compressibility, the maximum strain of CTVL test is $19.89 \%$, and the maximum compression of VTVL test can reach $18.16 \%$. The results of CTVL compression tests show that when the soil temperature is in the range of severe phase change $\left(-1.5^{\circ} \mathrm{C}-0^{\circ} \mathrm{C}\right)$, the temperature change has the greatest influence on the compression coefficient of soil. The result of VTVL compression test shows that some additional deformation occurs under the action of low temperature. The additional deformation is further increased when the soil is under high consolidation pressure and in the severe phase change $\left(-1.5^{\circ} \mathrm{C}-0^{\circ} \mathrm{C}\right)$.
\end{abstract}

Keywords: Freezing-thawing layer; Soft soil; Compression coefficient; Additional deformation.

\section{INTRODUCTION}

Permafrost areas near high-latitude coasts around the Arctic or Antarctica are greatly affected due to global climate change. Many studies have reported evidence of permafrost degradation in these areas due to global warming (Harrison, 1991; Johannessen, 1999; Zimov et al., 2006; Bhatt et al., 2010; Screen and Simmonds, 2010). Climate change has caused environmental changes in some areas (Shim et al., 2013; Shim et al., 2015). Due to global warming, permafrost is degrading, and seasonal permafrost is increasing. The ground strength of permafrost in high latitudes decreases due to thawing, and the ground surface in mountainous areas becomes unstable (Pachauri and Reisinger 2007). The permafrost degradation in northeast of China is regionally increasing, with the south boundary moving northward, the active layer deepening, the local permafrost islands disappearing, the permafrost temperature rising, thickness thinning, stability decreasing, etc. There is a wide range of soft soil in HulunBuir area, which is northeast Inner Mongolia, and the frost period is long. There is no freezing state in the 
soil layer from June to October. Its compression characteristics are greatly affected by temperature. The comprehensive influence of frozen soil condition and seasonal factors must be fully considered in engineering design and construction.

In order to ensure the stability of foundation in permafrost region, it is important to study the compressive properties of soil. Many scholars have made great efforts to study the compressive properties of permafrost. However, due to the complexity of test conditions and problems themselves, former researchers mainly focused on high temperature permafrost, and the compressive tests were performed by the methods of constant temperature with variable load and variable temperature under constant load. Zhu and Zhang (1982) studied the frozen subclay of Fenghuo volcano in Qinghai-Tibet Plateau and frozen medium sand in Lanzhou, analyzed the elastic deformation and compression deformation characteristics of frozen soil, and obtained the relationship between the compression coefficient of frozen soil and temperature. Zheng et al. (2009) concluded that the strain of frozen soil with a temperature range of $-1.5^{\circ} \mathrm{C}$ to $-1.0^{\circ} \mathrm{C}$ was less than $1 \%$ of the total strain, and the strain with a temperature range of $-0.5^{\circ} \mathrm{C}$ to $-0.3^{\circ} \mathrm{C}$ was more than $70 \%$ of the total strain. Su et al. (2013) obtained the volume compression coefficient of frozen soil under CTVL test conditions. It was found that, with an increase in ice content, the content of unfrozen water in frozen soil decreased, and the compression coefficient also decreased. Ruan et al. (2014) conducted constant temperature load test and constant load temperature test. The result showed that the compression index of high temperature and high content frozen soil was greater than 0.15 . The compression coefficient was greater than $0.2 \mathrm{MPa}^{-1}$ under CTVL test. At constant load and variable temperature condition, the compression coefficient increased significantly with an increase in temperature. When the temperature rose to $0.3{ }^{\circ} \mathrm{C}$, the compression coefficient was $0.29 \mathrm{MPa}^{-1}$. Liu et al. (2011) performed experiments with two test conditions of constant temperature and variable temperature under constant load. The influences of pore water pressure, temperature, and loading on the test results were analyzed. The results showed that pore water pressure in high temperature frozen soil was largely affected by loading. The higher the temperature, the faster the response of pore water pressure to loading. Cai (2015) conducted creep tests on high temperature frozen soil in laboratory. By comparing the experimental data, an empirical model suitable for triaxial creep characteristics of sandy silt with high temperature and ice content in Qinghai-Tibet region was selected. Yao et al. (2018) carried out a series of $\mathrm{K}_{0}$ compression tests under different constant additional loads and gradually increasing temperature. A model was established to describe the effect of temperature rise on the creep behavior of frozen soil. Yang et al. (2015) conducted unconstrained compression tests at temperatures ranging from $-0.7^{\circ} \mathrm{C}$ to $-11.6^{\circ} \mathrm{C}$. The effects of temperature, dry density, moisture content, and sample orientation on mechanical properties were discussed. At present, there are few studies on the compression tests of frozen soil under compression.

Generally, there are several principles for foundation design in permafrost areas: the principle of protecting permafrost refers to the freezing foundation during construction and operation; the principle of allowable melting refers to controlling permafrost foundation to melt at allowable rate during operation; and the principle of premelting refers to prethawing or digging and replacing fill (Cheng and Ma, 2006). In the construction and operation of Qinghai-Tibet Railway, the principle of protecting frozen soil was the most widely used method. However, the construction of road changes not only the temperature of frozen soil under the roadbed, but also the stress state. Many on-site monitoring data show that even if the permafrost under the roadbed does not melt, there will be a large compressive deformation in the depth range of geothermal change due to the action of roadbed filling and driving load (Yu and Yan, 1986; Phukan, 1983; Oluremi, JR et al., 2020). Considering the overall climate and environment in the seasonal frozen area, it is obviously unsuitable to adopt the principle of protecting frozen soil. The principle of prethawing requires prethawing of frozen soil or digging and replacing fill. This method involves huge work quantity and high cost.

Under the dual effects of climate change and engineering activities, the compression of frozen soil in the freezing-thawing layer during construction is actually a process of variable temperature and load. According to the 
characteristics of long freezing time and short construction period of soft soil in cold region, this paper aims to perform an indoor compression test of frozen soft soil under temperature control condition by refitting uniaxial consolidation instrument. Furthermore, this paper studies the variation rule of compression characteristics of freezing-thawing soft soil in construction process and explores the feasibility of construction when frozen soil has not melted.

\section{TEST CONDITIONS AND METHODS}

\section{Test Instrument}

The test instrument was composed of GZQ-1 automatic consolidation instrument and self-made temperature control system (Figure 1). The temperature control system consisted of a compressor, a temperature sensor, a temperature control room, and a numerical control instrument. During the test, the consolidation instrument was placed in the temperature control room, and the temperature sensor was inserted into another similar sample prepared according to the test plan (Figure 3). The required test temperature was obtained by adjusting the numerical control instrument. Through temperature setting, the response temperature of the control system was set at $\pm 0.3^{\circ} \mathrm{C}$. A PT100 temperature sensor was used to monitor the temperature of the specimen with an accuracy of $(0.15 \pm 0.002 \mathrm{~T})^{\circ} \mathrm{C}$.

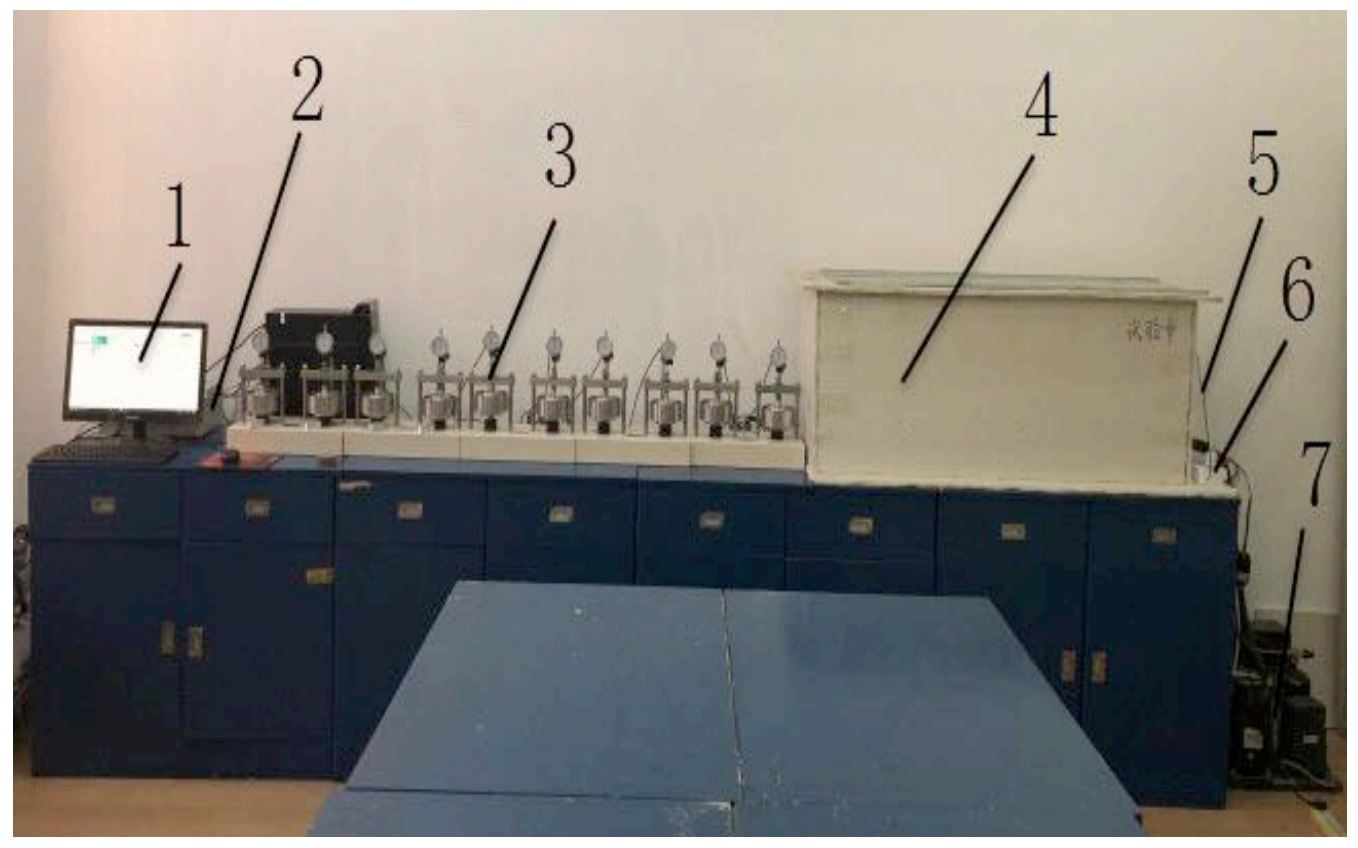

1 - computer, 2 - data acquisition Instrument, 3-consolidometer, 4-temperature control room, 5-temperature sensor, 6-numerical control instrument, 7 -refrigeration compressor

Figure 1. Picture of test equipment. 


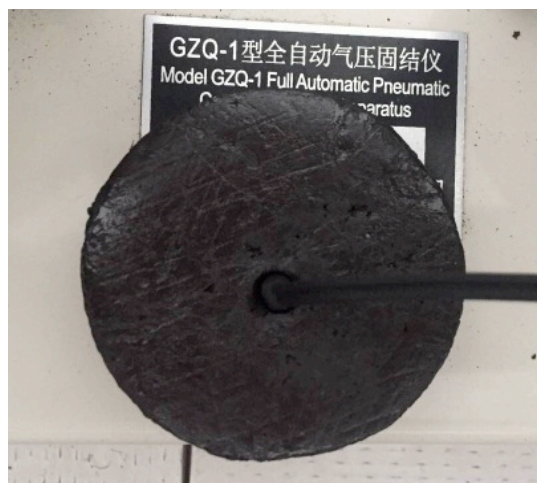

Figure 3. Temperature monitoring sample (temperature control standard).

\section{Test Material}

Test soil was taken from the soft soil of Labdarin-Hadatu first-class highway foundation from a depth of 1.2$1.5 \mathrm{~m}$. The physical properties of the soft soil were tested according to the rules of highway geotechnical test. The results are shown in Table 1. The gradation curve of the soil is shown in Figure 2.

Table 1. Physical properties of test soil samples.

\begin{tabular}{|c|c|c|c|c|}
\hline $\begin{array}{c}\text { Specific gravity } \\
G S\end{array}$ & $\begin{array}{c}\text { Natural moisture content } \\
\omega(\%)\end{array}$ & $\begin{array}{c}\text { Liquid limit } \\
\omega_{L}(\%)\end{array}$ & $\begin{array}{c}\text { Plastic limit } \\
\omega_{P}(\%)\end{array}$ & $\begin{array}{c}\text { Plasticity index } \\
I_{p}(\%)\end{array}$ \\
\hline 2.74 & 38.05 & 53.16 & 30.00 & 23.16 \\
\hline
\end{tabular}

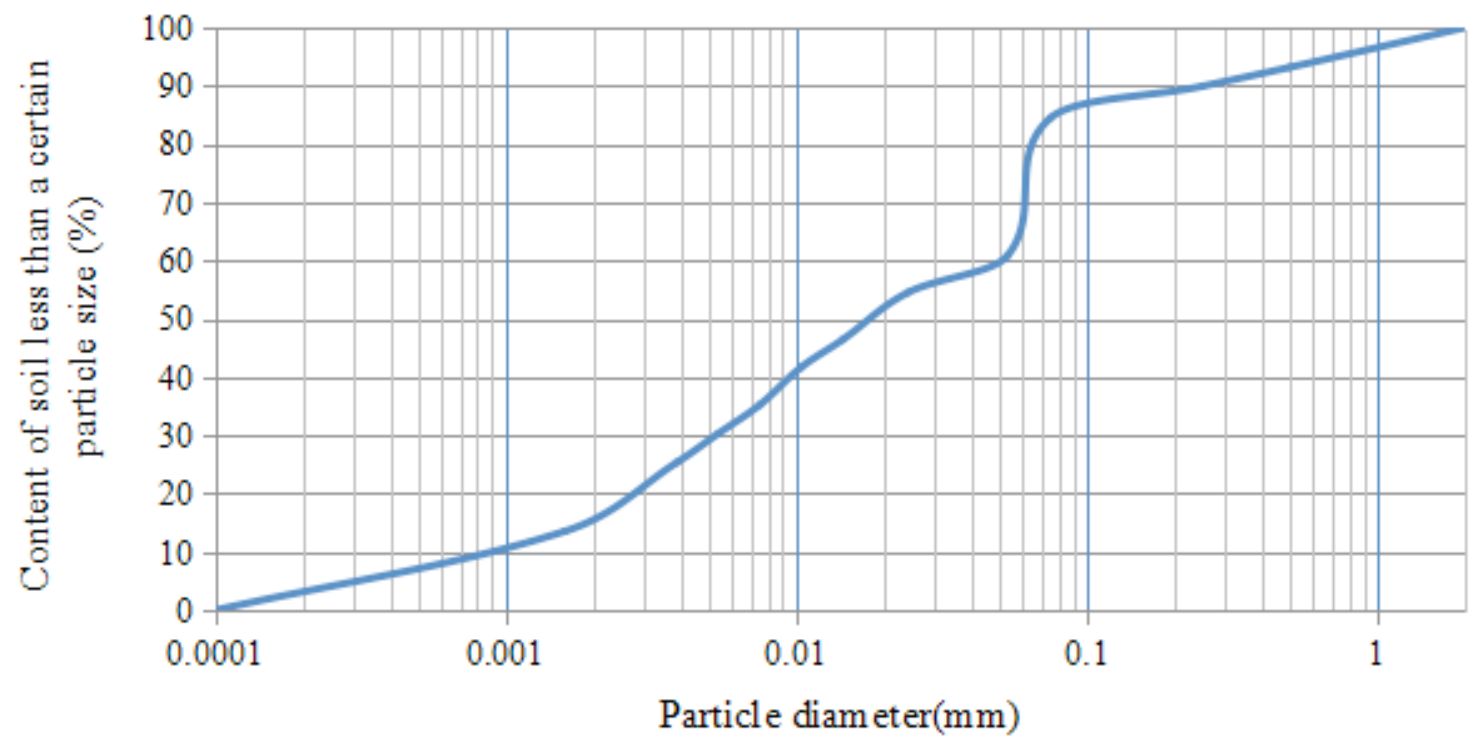

Figure 2. The gradation curve of test soil. 


\section{Test Scheme}

Compression tests were automatically loaded by a pneumatic consolidation apparatus. The size of the cylindrical specimen used in this study was $61.8 \mathrm{~mm}$ in diameter and $20 \mathrm{~mm}$ in height. Referring to the field condition of the soil sample, the moisture content of the specimen was set to $38 \%$, the dry density was $1.26 \mathrm{~g} / \mathrm{cm}^{3}$, and the degree of saturation was $88.61 \%$. Three same samples were prepared under each test condition. Considering the actual loading conditions of subgrade and the requirements of test scheme, the consolidation pressure was designed to be $0.05,0.1,0.2,0.4$, and $0.8 \mathrm{MPa}$. The frost period of soil layer in northeastern Inner Mongolia lasts for seven months, and there is no freezing state in only five months from June to October. The construction time is usually six months, and the treatment depth of soft soil layer is $0.5 \mathrm{~m}$. In order to discuss the possibility of speeding up construction progress and beginning construction ahead of the schedule, and according to the results of temperature monitoring on site, the temperature of the $0.5 \mathrm{~m}$ deep soil layer in Hulunbeier area in late April was noted. The temperature was approximately $-3^{\circ} \mathrm{C}$, suggesting that the operation of construction equipment is feasible at this temperature. According to a previous research (Zheng et al. 2009), the water in saturated clay in the area was undergoing severe phase change, so the lowest temperature of the test was set at $-3^{\circ} \mathrm{C}$. In order to facilitate the analysis of the test results, the test temperatures were $-3,-1.5,0,1.5$, and $3^{\circ} \mathrm{C}$, each of which lasted for 24 hours.

(1) The test scheme is shown in Table 2. Considering the compression characteristics of the freezing-thawing layer of the frozen soil at different temperatures, the CTVL test, i.e., the traditional step loading compression test, recorded the deformation of samples 24 hours after each loading stage to meet the stability criterion. Temperature was preset, and when constant temperature was obtained in the control room, the specimen was loaded by using the consolidation instrument for 24 hours.

(2) In order to study the compression characteristics of the freezing-thawing soft soil under different load levels and temperature combinations, the VTVL tests were consistent with the above two (CTVL test and VTVL test) test methods. The consolidation pressure and temperature grade were adjusted every 24 hours. The test plan is shown in Table 3.

Table 2. Constant Temperature Variable Load Test Plan.

\begin{tabular}{|c|c|c|c|c|c|c|}
\hline \multirow{2}{*}{ Test number } & Temperature $\left(C^{\circ}\right)$ & \multicolumn{5}{|c|}{ Consolidation pressure (MPa) } \\
\hline 1 & -3 & 0.05 & 0.1 & 0.2 & 0.4 & 0.8 \\
\hline 2 & -1.5 & 0.05 & 0.1 & 0.2 & 0.4 & 0.8 \\
\hline 3 & 0 & 0.05 & 0.1 & 0.2 & 0.4 & 0.8 \\
\hline 4 & 1.5 & 0.05 & 0.1 & 0.2 & 0.4 & 0.8 \\
\hline 5 & 3 & 0.05 & 0.1 & 0.2 & 0.4 & 0.8 \\
\hline
\end{tabular}


Table 3. Variable Temperature and Variable Load Test Plan (MPa).

\begin{tabular}{|c|c|c|c|c|c|}
\hline \multirow{2}{*}{ Test number } & \multicolumn{5}{|c|}{ Temperature $\left(\mathrm{C}^{\circ}\right)$} \\
\hline & -3 & -1.5 & 0 & 1.5 & 3 \\
\hline 6 & 0.05 & 0.1 & 0.2 & 0.4 & 0.8 \\
\hline 7 & 0.05 & 0.1 & 0.2 & $0.4 、 0.8$ & - \\
\hline 8 & 0.05 & 0.1 & $0.2,0.4$ & 0.8 & - \\
\hline 9 & 0.05 & 0.1 & $0.2,0.4,0.8$ & - & - \\
\hline 10 & 0.05 & $0.1,0.2$ & 0.4 & 0.8 & - \\
\hline 11 & 0.05 & $0.1 、 0.2$ & $0.4 、 0.8$ & - & - \\
\hline 12 & 0.05 & $0.1,0.2 、 0.4$ & 0.8 & - & - \\
\hline 13 & 0.05 & $0.1,0.2,0.4,0.8$ & - & 一 & - \\
\hline 14 & $0.05 、 0.1$ & 0.2 & 0.4 & 0.8 & - \\
\hline 15 & $0.05,0.1$ & 0.2 & $0.4,0.8$ & - & - \\
\hline 16 & $0.05,0.1$ & $0.2 、 0.4$ & 0.8 & - & - \\
\hline 17 & $0.05,0.1$ & $0.2,0.4,0.8$ & 一 & - & - \\
\hline 18 & $0.05,0.1,0.2$ & 0.4 & 0.8 & - & 一 \\
\hline 19 & $0.05,0.1,0.2$ & $0.4 、 0.8$ & - & - & - \\
\hline 20 & $0.05,0.1,0.2 、 0.4$ & 0.8 & - & - & - \\
\hline
\end{tabular}

\section{ANALYSIS OF TEST RESULTS}

\section{Constant Temperature Variable Load Test}

The curves of strain and consolidation pressure with time in CTVL test are shown in Figure 4. Figure 4 shows that the compressibility of soil was largely affected by temperature. When the temperature of the sample was above $0^{\circ} \mathrm{C}$, load at all levels produced a relatively large strain at the initial stage of loading, and the deformation rate was relatively large. With the extrusion of pore water in the soil, the soil sample was compacted, and the compressibility of the soil decreased continuously. After 120 hours, the strain value became stable, and the strain rate tended to zero (Figure 4a), which is similar to the observation in a conventional method. Compression test results were consistent; when the sample temperature was negative, the strain development curve was relatively smooth (Figure $4 \mathrm{~b}$ ). The main reason was that the water in the soil froze into ice under negative temperature, the soil structure was only slightly changed, the compression modulus value was high, and the compression amount was relatively small. 


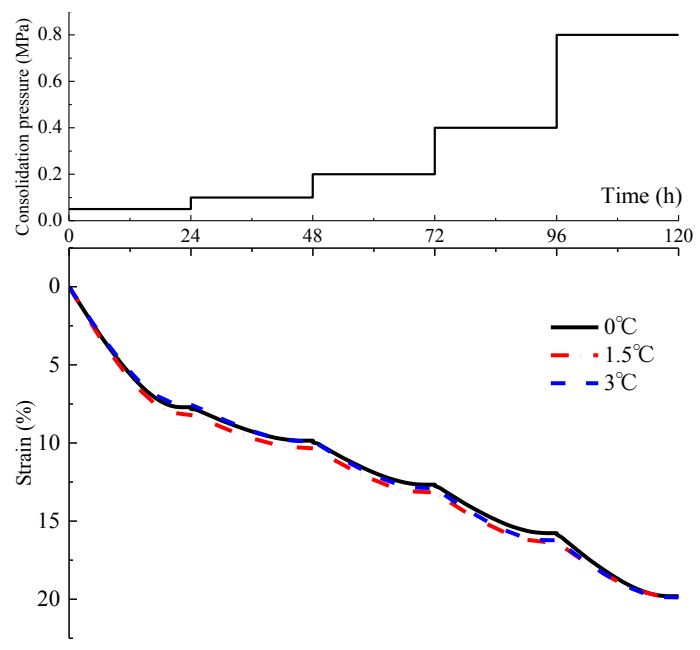

(a) $T \geq 0^{\circ} \mathrm{C}$

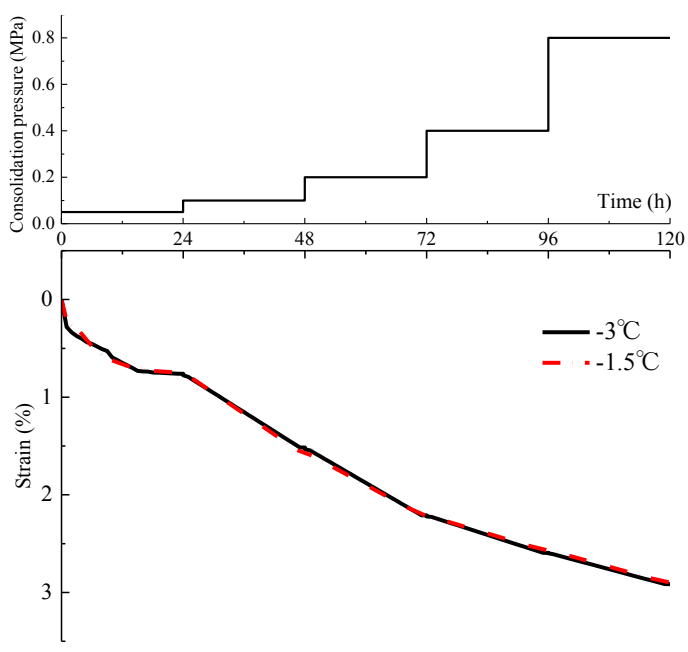

(b) $T<0^{\circ} \mathrm{C}$

Figure 4. Curves of Relation between Strain, Consolidation Pressure, and Time in CTVL Tests.

Compression coefficient is an important index to evaluate the soil compressibility. The greater the compression coefficient, the higher the soil compressibility. In this study, compression coefficient of soft soil in Hulun Buir area under different test conditions was obtained by calculation and is presented in Table 4 .

Table 4. Summary table of compression coefficient of soft soil under CTVL tests (MPa $\left.{ }^{-1}\right)$.

\begin{tabular}{|c|c|c|c|c|c|c|c|c|c|c|}
\hline $\begin{array}{c}\text { Tempe- } \\
\text { rature } \\
\left(\mathrm{C}^{\circ}\right)\end{array}$ & $\begin{array}{c}\text { Consoli } \\
\text { dation } \\
\text { pressure } \\
(\mathrm{MPa})\end{array}$ & $\begin{array}{c}\text { Compres } \\
\text {-sibility }\end{array}$ & $\begin{array}{c}\text { Consoli } \\
\text { dation } \\
\text { pressure } \\
(\mathrm{MPa})\end{array}$ & $\begin{array}{c}\text { Compress- } \\
\text { ibility }\end{array}$ & $\begin{array}{c}\text { Consolidatio } \\
\text { n pressure } \\
(\mathrm{MPa})\end{array}$ & $\begin{array}{c}\text { Compress } \\
\text {-ibility }\end{array}$ & $\begin{array}{c}\text { Consolidatio } \\
\text { n pressure } \\
(\mathrm{MPa})\end{array}$ & $\begin{array}{c}\text { Compress } \\
\text {-ibility }\end{array}$ & $\begin{array}{c}\text { Consolidatio } \\
\mathrm{n} \text { pressure } \\
(\mathrm{MPa})\end{array}$ & $\begin{array}{c}\text { Compress } \\
\text {-ibility }\end{array}$ \\
\hline 3 & 0.05 & 0.329 & 0.1 & 0.301 & 0.2 & 0.150 & 0.4 & 0.042 & 0.8 & 0.017 \\
\hline-1.5 & 0.05 & 0.372 & 0.1 & 0.303 & 0.2 & 0.141 & 0.4 & 0.038 & 0.8 & 0.018 \\
\hline 0 & 0.05 & 2.123 & 0.1 & 1.630 & 0.2 & 0.910 & 0.4 & 0.367 & 0.8 & 0.191 \\
\hline 1.5 & 0.05 & 2.132 & 0.1 & 1.626 & 0.2 & 0.913 & 0.4 & 0.374 & 0.8 & 0.187 \\
\hline 3 & 0.05 & 2.144 & 0.1 & 1.636 & 0.2 & 0.918 & 0.4 & 0.376 & 0.8 & 0.186 \\
\hline
\end{tabular}

Table 4 shows that the compression coefficient of high-temperature frozen soil was not different from that of low-temperature frozen soil when the specimen was at the critical temperature $\left(-1.5^{\circ} \mathrm{C}\right)$. The main reason was that when the temperature was lower than $-1.5^{\circ} \mathrm{C}$, the content of unfrozen water in the frozen soil sample was small, most of the pores were filled with ice, and it was difficult to compress the specimen (Ma, 2014). When the temperature increased to $0^{\circ} \mathrm{C}$, the compression coefficient increased sharply. For example, when the consolidation pressure was $0.05 \mathrm{MPa}$, the compression coefficient of the specimen at $0^{\circ} \mathrm{C}$ increased by $471 \%$ when compared with that at $-1.5^{\circ} \mathrm{C}$. However, when the temperature was increased from $1.5^{\circ} \mathrm{C}$ to $3^{\circ} \mathrm{C}$, the compression coefficient was comparable to that at $0^{\circ} \mathrm{C}$, which indicates that the temperature had a significant effect on the compression characteristics of soil only when the soil was in the severe phase change temperature $\left(-1.5^{\circ} \mathrm{C}-0^{\circ} \mathrm{C}\right)$.

Figure 5 shows the variation of compression coefficient with consolidation pressure at different temperatures. The compression coefficient decreased gradually with an increase in consolidation pressure, and the development 
trend was basically the same for different specimens. From Figure 5, it can be seen that the compression coefficient of soft soil at positive temperature was much larger than that at the negative temperature, but the difference decreased with an increase in pressure. The main reason was that pore water in the soft soil froze into ice at negative temperature, ice crystals, and soil skeleton resisted the external pressure together, and eventually, ice crystals were broken partially with soil particles under pressure. On the other hand, under the action of pressurethaw, pore ice melted and was squeezed out with unfrozen water, which produced certain compressive deformation. However, under normal temperature, the dry density of the test soil increased due to the discharge of the pore water, and the movement of soil particles was relatively difficult. At the same time, the deformation of soil particles themselves was relatively small, so the effect of high pressure was relatively small at normal temperature. When the temperature was positive or negative, the compression coefficient was close to the consolidation pressure curve.

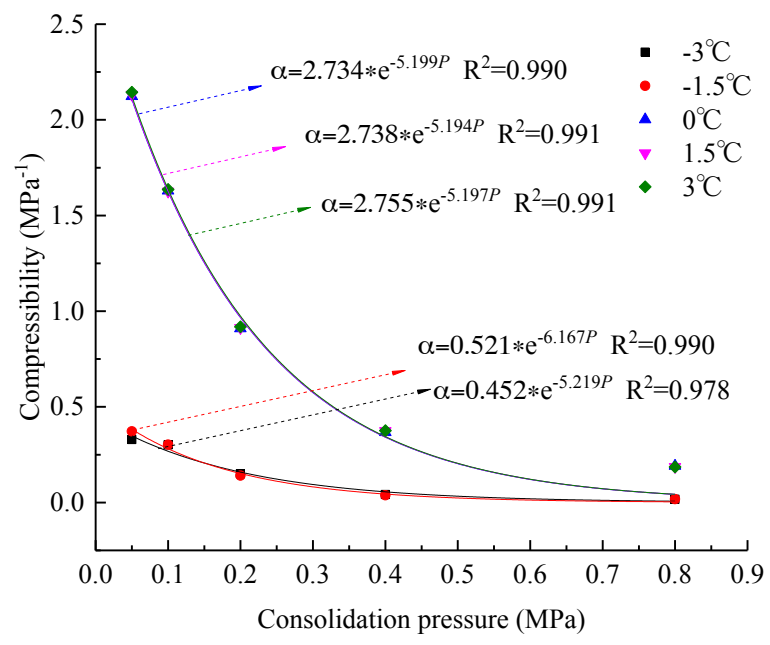

Figure 5. Compression coefficient curve of soft soil at different temperature.

Figure 5 shows that the compressibility coefficient of soft soil varied exponentially with the consolidation pressure, which can be expressed by the following equation:

$$
a=A \cdot \exp (B \cdot P)
$$

where $a$ is the compression coefficient, and $P$ is the consolidation pressure. The unknown coefficients $\mathrm{A}$ and $\mathrm{B}$ are determined from soil quality, temperature, and so on.

\section{Variable Temperature and Variable Load Test}

Figure 6 shows the curves of strain, temperature, and consolidation pressure with time in the variable temperature and load test. Taking test No.6 as an example, in the negative temperature range, the strain developed slowly and produced only part of the strain at the moment of loading. The reason was similar to the constant temperature load test under negative temperature. The water in the soil froze into ice under the action of negative temperature, and the formed glue froze with the soil particles to bear the load. The stiffness increased, so the compressive capacity was enhanced. When the temperature increased to $0^{\circ} \mathrm{C}$, the ice in the soil gradually transformed into water and was constantly extruded under pressure. However, because the increase in internal temperature of the specimen was a slow process, a small strain was generated at the initial stage of the loading. When the temperature increased to $1.5^{\circ} \mathrm{C}$, all the ice in the soil was transformed into water. On the other hand, 
some large particles in the soil had transformed into small particles due to ice crystals formation in the freezing process. During the process of melting, ice crystals melted into water, and some water migrated in reverse. Although the connectivity of soil particles and the pore structure recovered to a certain extent during the melting process, a new structural system was formed after freezing, which was different from the original internal structure. As the soil structure could not restore to the initial state before freezing, the strength of soil was decreased. Consequently, under the action of high consolidation pressure, the specimen produced large compression deformation. After 120 hours, the specimen attained full compression, the deformation rate tended to zero, and the compression amount remained stable. From the strain-time curves (a), (b), and (c) of Figure 6, it can be seen that the compression deformation of frozen soil in the transition period from $-1.5^{\circ} \mathrm{C}$ to $0^{\circ} \mathrm{C}$ could be divided into three stages, namely, respectively, instantaneous deformation, unstable compaction, and stable deformation. The corresponding deformations were, respectively, called instantaneous deformation (mainly elastic deformation), seepage migration deformation, and attenuated creep deformation (Tsytovich, 1975). The seepage migration deformation is mainly caused by the migration and exudation of unfrozen water and the compression of pores, which can be completed shortly after loading (transient deformation is completed). The attenuated creep deformation is related to the pressure melting of ice, water migration, recrystallization, and rearrangement of soil particles, which requires a long stabilization time.

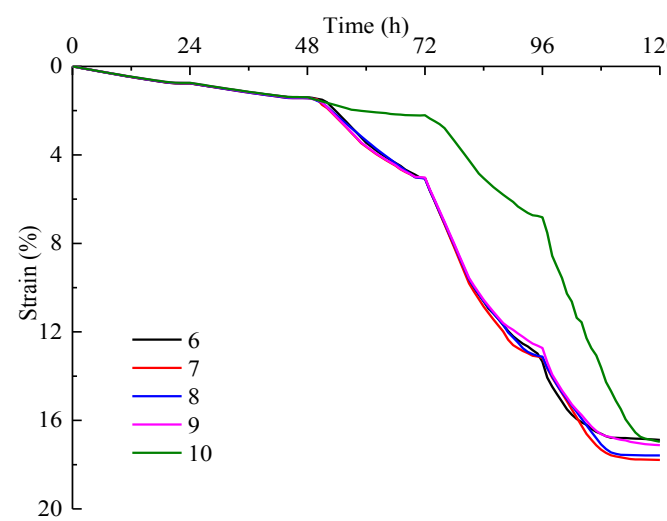

(a) Test number 6-10

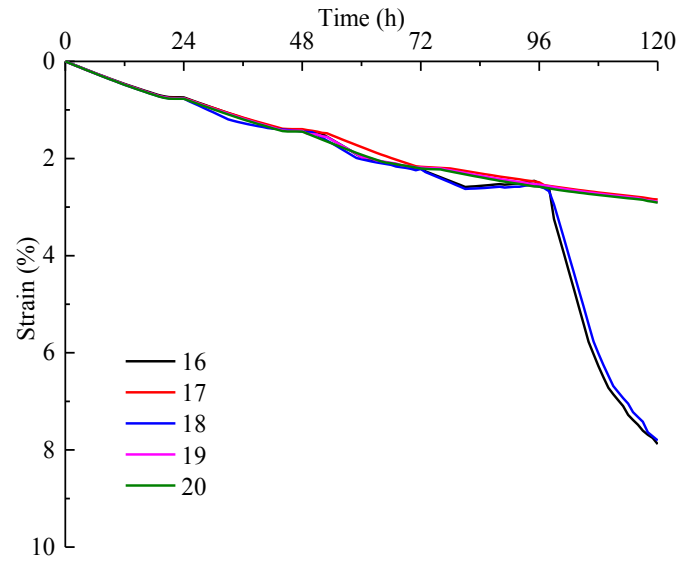

(c) Test number 16-20

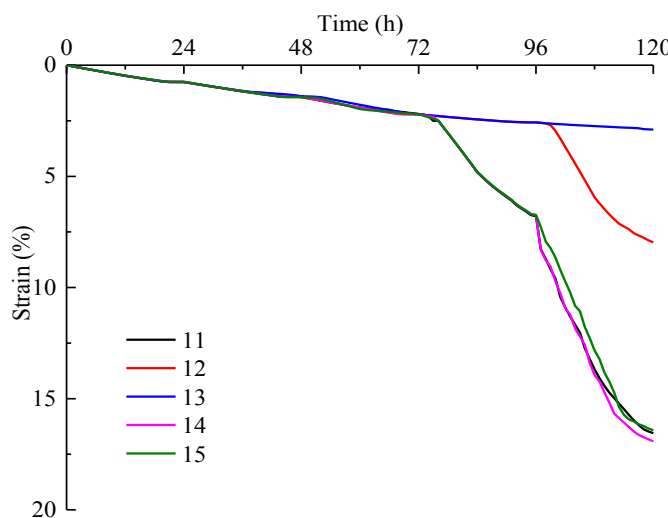

(b) Test number 11-15

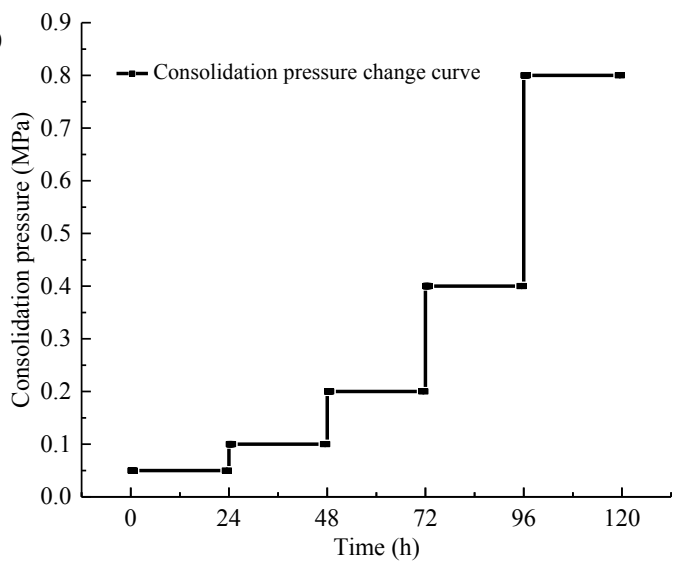

(d) Load and temperature curves

Figure 6. Variable temperature and load test strain, load-time curve. 
From the above two tests, it can be concluded that the consolidation pressure has a great influence on the compressive properties of soil, and when the soil temperature is in the range of -1.5 to $0^{\circ} \mathrm{C}$, the variable temperature and load test can be divided into four cases, as shown in Table 5.

Table 5. Four cases of variable temperature and load test.

\begin{tabular}{|c|c|c|}
\hline $\begin{array}{c}\text { Test } \\
\text { case }\end{array}$ & Test number & \\
\hline 1 & $13,17,19,20$ & Explain \\
\hline 2 & $6 、 7 、 8 、 9$ & When the consolidation pressure is $0.2 \mathrm{MPa}$, the temperature is not negative. \\
\hline 3 & $10,11,14,15$ & When the consolidation pressure is $0.4 \mathrm{MPa}$, the temperature is not negative. \\
\hline 4 & $12,16 、 18$ & When the consolidation pressure is $0.8 \mathrm{MPa}$, the temperature is not negative. \\
\hline
\end{tabular}

An analysis was made in this study according to the four cases listed in Table 5. Test case 1 showed that the whole process of compression was in negative temperature, and the maximum strains produced at the end of the four cases were not significantly different $(2.90 \%, 2.85 \%, 2.90 \%$, and $2.91 \%$, respectively). This phenomenon indicates that the compression deformation of the specimen under consolidation pressure is limited when the soil temperature is below or equal to $-1.5^{\circ} \mathrm{C}$. Test case 2 showed that the consolidation pressure was limited for the first two stages $(0.05,0.1 \mathrm{MPa})$ of the compression test. When the consolidation pressure was $0.2 \mathrm{MPa}$, the test temperature gradually increased from $-1.5^{\circ} \mathrm{C}$ to $0^{\circ} \mathrm{C}$ or above. After 24 hours of consolidation pressure $(0.2 \mathrm{MPa})$, the strain of the four groups of test specimens was between $5.025 \%$ and $5.065 \%$, and the maximum strain difference at the end of the test was $1.035 \%$. This indicates that when the soil temperature is greater than or equal to $0{ }^{\circ} \mathrm{C}$, the compression deformation of the sample is close to that of the noncompression deformation. The compressive properties of soil having negative temperature were similar. Test case 3 showed that temperature was negative at the first three consolidation pressures $(0.05,0.1$, and $0.2 \mathrm{MPa})$, and the test temperature increased gradually from $-1.5^{\circ} \mathrm{C}$ to $0{ }^{\circ} \mathrm{C}$ and above at the consolidation pressure of $0.4 \mathrm{MPa}$. The strain of the four groups of test specimens was $6.74 \%$ to $6.82 \%$ after 24 hours of applying the consolidation pressure of $0.4 \mathrm{MPa}$. The maximum strain was $7.97 \%, 7.88 \%$, and $7.81 \%$ at the end of the test, when the consolidation pressure was 0.8 $\mathrm{MPa}$, and the test temperature increased gradually from $-1.5^{\circ} \mathrm{C}$ to $0^{\circ} \mathrm{C}$ or above.

The deformation data were converted into compression coefficients. The curve of compression coefficients of soft soil with consolidation pressure is shown in Figure 7. The variation trend can be described by the following equation: 


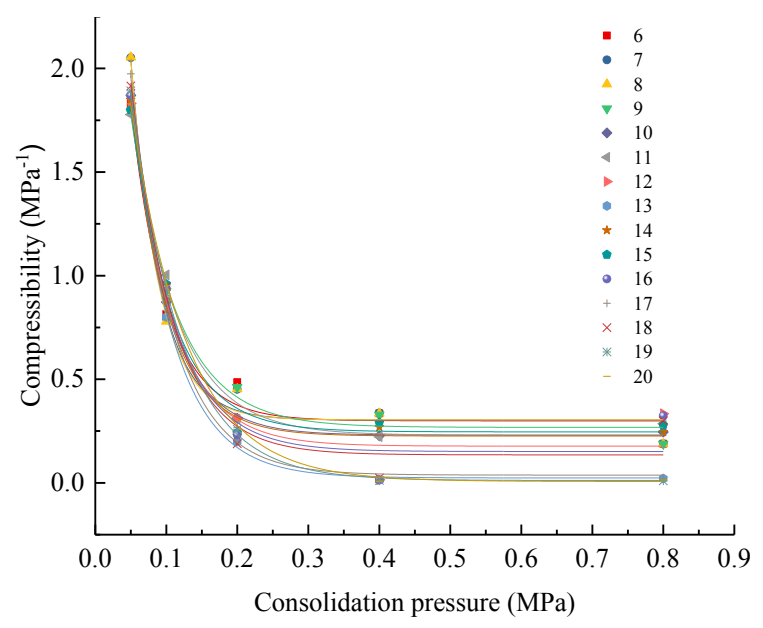

Figure 7. Compression coefficient versus consolidation pressure.

$$
a=A \exp (B \cdot P)+C
$$

where $a$ is the compression coefficient, and $P$ is the consolidation pressure. The unknown coefficients A, B, and $\mathrm{C}$ are determined from soil quality, temperature, and so on.

Table 6. Regression parameters of compression coefficient versus consolidation pressure.

\begin{tabular}{|c|c|c|c|c|c|}
\hline Number & Parameter $A$ & Parameter $B$ & Parameter $C$ & Equation & $R^{2}$ \\
\hline 6 & 4.126 & 50.084 & 0.299 & $\mathrm{y}=4.126 \mathrm{e}^{(-\mathrm{x} / 50.084)}+0.299$ & 0.984 \\
\hline 7 & 5.866 & 41.212 & 0.303 & $\mathrm{y}=5.866 \mathrm{e}^{(-\mathrm{x} / 41.212)}+0.303$ & 0.989 \\
\hline 8 & 6.066 & 40.132 & 0.304 & $\mathrm{y}=6.066 \mathrm{e}^{(-\mathrm{x} / 40.132)}+0.304$ & 0.988 \\
\hline 9 & 3.291 & 64.152 & 0.268 & $\mathrm{y}=3.291 \mathrm{e}^{(-\mathrm{x} / 64.152)}+0.268$ & 0.992 \\
\hline 10 & 4.240 & 52.683 & 0.230 & $\mathrm{y}=4.240 \mathrm{e}^{(-\mathrm{x} / 52.683)}+0.230$ & 0.999 \\
\hline 11 & 3.377 & 64.908 & 0.230 & $\mathrm{y}=3.377 \mathrm{e}^{(-\mathrm{x} / 64.908)}+0.230$ & 0.993 \\
\hline 12 & 3.882 & 58.640 & 0.177 & $\mathrm{y}=3.882 \mathrm{e}^{(-\mathrm{x} / 58.640)}+0.177$ & 0.975 \\
\hline 13 & 4.281 & 59.276 & 0.024 & $\mathrm{y}=4.281 \mathrm{e}^{(-\mathrm{x} / 59.276)}+0.024$ & 0.999 \\
\hline 14 & 4.282 & 51.808 & 0.226 & $\mathrm{y}=4.282 \mathrm{e}^{(-\mathrm{x} / 51.808)}+0.226$ & 0.994 \\
\hline 15 & 3.778 & 56.996 & 0.246 & $\mathrm{y}=3.778 \mathrm{e}^{(-\mathrm{x} / 56.996)}+0.246$ & 0.989 \\
\hline 16 & 4.003 & 59.618 & 0.151 & $\mathrm{y}=4.003 \mathrm{e}^{(-\mathrm{x} / 59.618)}+0.151$ & 0.976 \\
\hline 17 & 4.435 & 59.904 & 0.037 & $\mathrm{y}=4.435 \mathrm{e}^{(-\mathrm{x} / 59.904)}+0.037$ & 0.997 \\
\hline 18 & 4.222 & 58.436 & 0.135 & $\mathrm{y}=4.222 \mathrm{e}^{(-\mathrm{x} / 58.436)}+0.135$ & 0.979 \\
\hline 19 & 3.818 & 70.311 & 0.011 & $\mathrm{y}=3.818 \mathrm{e}^{(-\mathrm{x} / 70.311)}+0.011$ & 0.999 \\
\hline 20 & 3.427 & 78.772 & 0.007 & $\mathrm{y}=3.427 \mathrm{e}^{(-\mathrm{x} / 78.772)}+0.007$ & 0.999 \\
\hline
\end{tabular}


According to the comparative analysis of the compression coefficient of soft soil with consolidation pressure under different test schemes as shown in Figure 7, the compression coefficient of soft soil under different test conditions decreased exponentially with an increase in consolidation pressure. The compression coefficient curve of soft soil with consolidation pressure at different temperatures was consistent with that in CTVL test (Figure 5), and the compression coefficient of VTVL test varied as square with consolidation pressure. Comparing equation (Equation 1) of compression coefficient with consolidation pressure of constant temperature and load-changing test, Equation 2 only added parameter $\mathrm{C}$ on the basis of Equation 1. Combining the results of VTVL test scheme (Table 3 ) and regression parameter $\mathrm{C}$ (Table 6), it can be assumed that parameter $\mathrm{C}$ is determined by temperature. Through the VTVL compression test scheme (Table 4), it can be seen that the test temperature of No. 6-20 was negative at the first two consolidation pressures $(0.05,0.1 \mathrm{MPa})$. When the consolidation pressure was $0.2 \mathrm{MPa}$, the test temperatures corresponding to different test numbers began to differ. As shown in Figure 7, when the consolidation pressure was in the range of 0.05-0.1 MPa, these curves, where the compression coefficient varied with the consolidation pressure under different test numbers, are basically coincident. Therefore, taking the consolidation pressure of $0.2 \mathrm{MPa}$ as the limit, the arithmetic average of temperature under each set of test numbers was obtained corresponding to the consolidation pressure of $0.2,0.4$, and $0.8 \mathrm{MPa}$. Thus, the relationship between the parameter $\mathrm{C}$ and the average temperature was obtained, as shown in Figure 8.

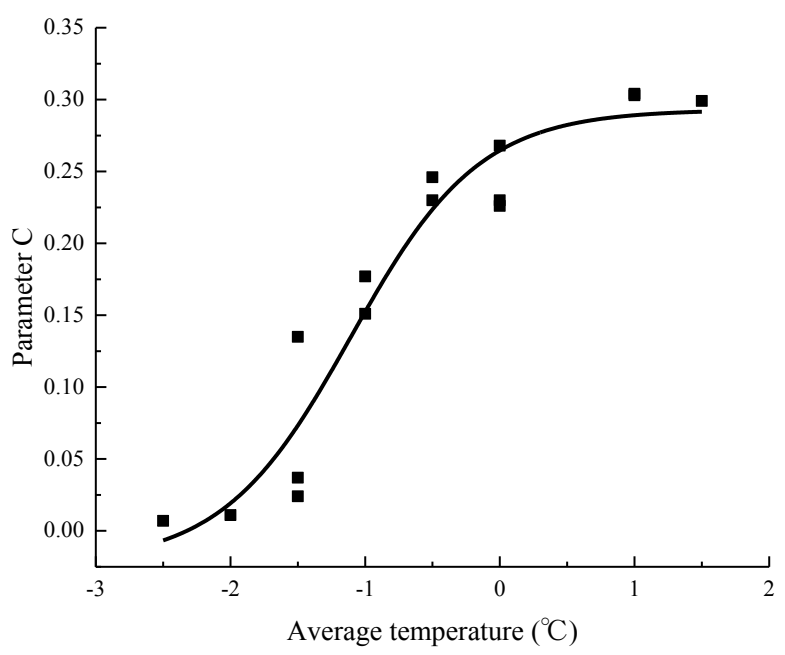

Figure 8. Curve of relationship between parameter $\mathrm{C}$ and average temperature.

Figure 8 shows that there was an approximate ' $\mathrm{S}$ ' curve relationship between the parameter $\mathrm{C}$ and the average temperature under the corresponding consolidation pressure of $0.2,0.4$, and $0.8 \mathrm{MPa}$. The curve appeared to be smooth when the temperature is below $-2{ }^{\circ} \mathrm{C}$. The growth rate of parameter $\mathrm{C}$ was relatively high when the temperature increased from $-1.5^{\circ} \mathrm{C}$ to $0^{\circ} \mathrm{C}$ and basically remained unchanged when the temperature was above $0^{\circ} \mathrm{C}$. This indicates that when the soil temperature increases from $-1.5^{\circ} \mathrm{C}$ to $0^{\circ} \mathrm{C}$, the compressive properties of the soil remain basically unchanged. This change tendency is consistent with the conclusions of the previous study. On the other hand, the variation of compression coefficient with consolidation pressure in the VTVL test was obtained by increasing parameter $\mathrm{C}$, which, in turn, was determined by an average temperature on the basis of the variation of compression coefficient with the consolidation pressure in constant temperature and load test.

In order to compare the results of the VTVL compression test with those of the CTVL compression test, the two tests were conducted for the same pressure values; these are $0.05,0.1,0.2,0.4$, and $0.8 \mathrm{MPa}$. The difference lied in the different temperature, which was the basis for evaluation. Taking test No. 6 as an example, the compression amount of 0.05 to $0.1 \mathrm{MPa}$ was differentiated from that of 0.05 to $0.1 \mathrm{MPa}$ under the constant 
temperature $\left(-3^{\circ} \mathrm{C}\right)$ variable load test. The difference was the additional compression caused by the increase in temperature. The curves of the relationship between additional compression and load under different schemes of the variable temperature and load test are shown in Figure 9.

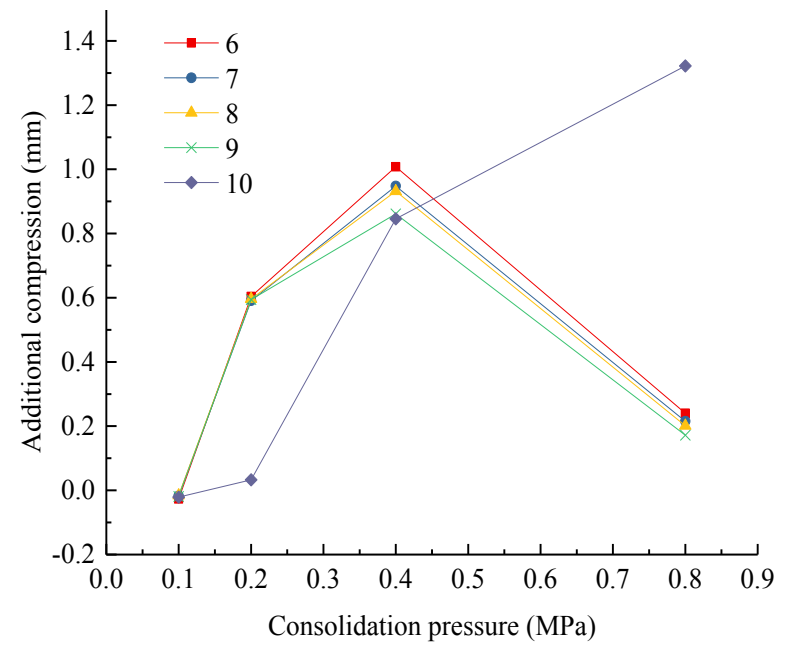

(a) Test number 6-10

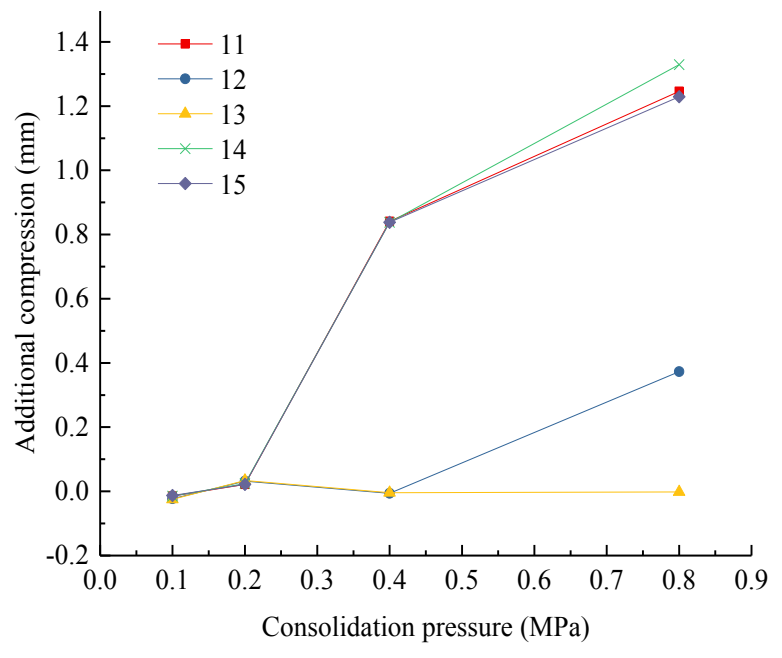

(b) Test number 11-15

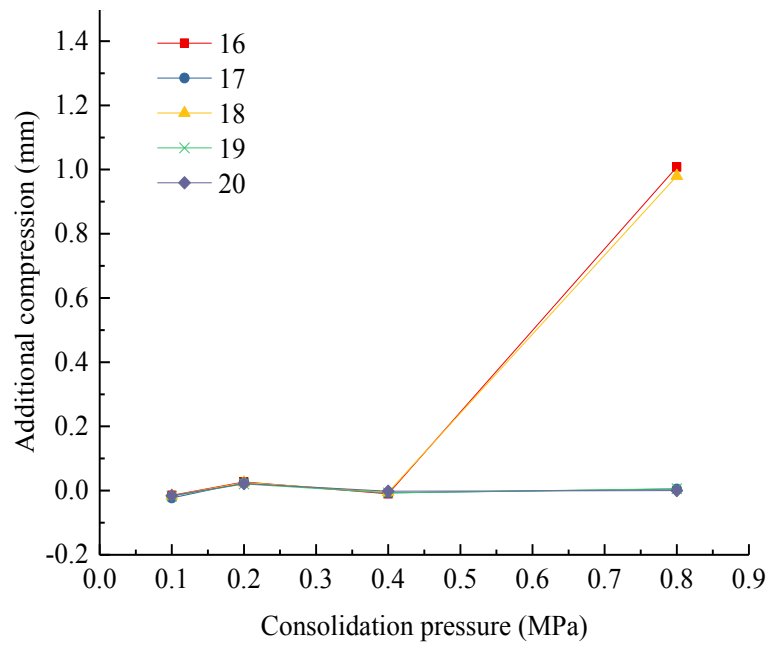

(c) Test number 16-20

Figure 9. Curve of relationship between additional compression and consolidation pressure.

Figure 9 shows that the additional compression caused by the temperature rise was $-0.027 \mathrm{~mm}$ at the beginning of the test 48 hours. The minus value might have been caused by the error of the test instrument even though the value is small. Meanwhile, the temperature was negative during the process of consolidation pressure being increased from 0.05 to $0.1 \mathrm{MPa}$. It can be concluded that temperature has little effect on the compression properties of soil when the temperature is negative. In the first $72 \mathrm{~h}$ of the compression test, the error caused by the test instrument was negligibly small. An additional compression of $0.604 \mathrm{~mm}$ appeared due to change in temperature. The main reason was that the temperature increased gradually from $-1.5^{\circ} \mathrm{C}$ to $0^{\circ} \mathrm{C}$ in the interval of 48 $72 \mathrm{~h}$, the frozen soil melted, the content of unfrozen water increased, and the pore water was squeezed out under 
pressure. Therefore, the additional compression caused by temperature was relatively larger at $96 \mathrm{~h}$ of the test. The peak value was $1.008 \mathrm{~mm}$. The main reason was that the pore ice in soil continued to melt, the pore water content continued to increase, and the pore water was continuously extruded under the action of a large pressure associated with an increase in temperature. In addition, the compression that could not occur under the action of negative temperature at low consolidation pressure was further released at this stage. Compression shrinkage was large. As the air and moisture in the soil pores were continuously squeezed out, the movement of the soil particles became increasingly difficult. Therefore, at the 120th hour of the test, the additional compression was quite small.

According to the above research results, temperature had a large influence on soil compression properties in the range of $-1.5^{\circ} \mathrm{C}-0^{\circ} \mathrm{C}$. Therefore, the compression coefficients corresponding to $-1.5^{\circ} \mathrm{C}-0^{\circ} \mathrm{C}$ in the VTVL test are compared with those corresponding to $-1.5^{\circ} \mathrm{C}$ in the CTVL test, and the calculated ratios are listed in Table 7.

Table 7. Ratio of Compression Coefficient of Variable Temperature and Load Test $\left(-1.5^{\circ} \mathrm{C}-0^{\circ} \mathrm{C}\right)$ to Compression Coefficient of Variable Temperature and Load Test.

\begin{tabular}{|c|c|c|c|c|c|}
\hline \multicolumn{6}{|c|}{ Consolidation pressure (MPa) } \\
\hline \multicolumn{2}{|c|}{$0.1-0.2$} & \multicolumn{2}{|c|}{$0.2-0.4$} & \multicolumn{2}{|c|}{$0.4-0.8$} \\
\hline $\begin{array}{c}\text { Test } \\
\text { number }\end{array}$ & $\begin{array}{l}\text { Compressibility } \\
\text { ratio }\end{array}$ & $\begin{array}{c}\text { Test } \\
\text { number }\end{array}$ & $\begin{array}{c}\text { Compressibility } \\
\text { ratio }\end{array}$ & $\begin{array}{c}\text { Test } \\
\text { number }\end{array}$ & $\begin{array}{c}\text { Compressibility } \\
\text { ratio }\end{array}$ \\
\hline 6 & 5.63 & 10 & 13.61 & 12 & 16.22 \\
\hline 7 & 5.53 & 11 & 13.08 & 16 & 16.17 \\
\hline 8 & 5.57 & 14 & 12.95 & 18 & 16.28 \\
\hline 9 & 5.55 & 15 & 12.95 & - & - \\
\hline
\end{tabular}

As Table 7 shows, when the temperature was in the range of $-1.5^{\circ} \mathrm{C}$ to $0^{\circ} \mathrm{C}$ and consolidation pressure was small (0.1-0.2 MPa), the compression coefficient ratio was relatively small. When the consolidation pressure was large (0.2-0.4 MPa and 0.4-0.8 MPa), the ratio of compression coefficient between the VTVL test and the CTVL test was relatively large. The larger compression coefficient in the VTVT test is attributed to the facts that (a) a larger consolidation pressure increased the melting phenomenon of permafrost, and (b) the pore water produced by the increasing temperature was squeezed out causing a larger compression deformation in the soil.

\section{DISCUSSION}

Compression properties of freezing-thawing soft soil under different loads and temperatures were studied by two experimental methods. The response of soft soil deformation to loading at constant temperature was studied by the CTVL test. Table 8 compares the maximum strain produced by the CTVL test and the VTVL test. The results show that the average strain was $2.91 \%$ at the negative temperature and $19.84 \%$ at the positive temperature, which indicates that the positive and negative temperatures had a large influence on the compressibility of soft soil. At the end of the test, the maximum strain corresponding to the VTVL test was smaller than that of the CTVL test. Taking test number 6 as an example, the specimen experienced the same pressure gradient as the CTVL $\left(3^{\circ} \mathrm{C}\right)$ test, but the specimen of test number 6 underwent five levels of temperatures, namely, $-3,-1.5,0,1.5$, and $3{ }^{\circ} \mathrm{C}$, and the final 
strain was the maximum response corresponding to the CTVL $\left(3^{\circ} \mathrm{C}\right)$ test. The strain variable value was less than $4.19 \%$, which indicates that the compression deformation produced by the test with changing temperature and load from negative temperature to positive temperature was small, even though, in the course of construction, certain additional compression occurred due to the changing temperature. If construction in the field is to be carried out earlier in the season, the additional settlement caused by temperature should be considered, and the additional settlement and loading rate should be controlled.

In the CTVL test, the strain step caused by loading on the strain development curve was steep and high. As the soil sample was continuously compressed, the strain step caused by later loading was relatively low, which indicates that the sensitivity of soil sample to loading was reduced due to compaction. In the VTVL test, with the temperature increasing, a larger strain appeared under the action of the higher temperature load. The duration for the deformation to reach stability was longer than that for the CTVL test, and the deformation had no obvious attenuation trend.

Table 8. Maximum strain produced by constant temperature and variable temperature load tests.

\begin{tabular}{|c|c|c|c|c|c|}
\hline $\begin{array}{c}\text { Test } \\
\text { number }\end{array}$ & $\begin{array}{l}\text { Test } \\
\text { name }\end{array}$ & Strain $(\%)$ & $\begin{array}{c}\text { Test } \\
\text { number }\end{array}$ & $\begin{array}{l}\text { Test } \\
\text { name }\end{array}$ & Strain $(\%)$ \\
\hline 1 & \multirow{5}{*}{$\begin{array}{l}\text { Constant temperature } \\
\text { and variable load }\end{array}$} & 2.92 & 11 & \multirow{10}{*}{$\begin{array}{l}\text { Variable temperature } \\
\text { and variable load }\end{array}$} & 15.24 \\
\hline 2 & & 2.90 & 12 & & 13.66 \\
\hline 3 & & 19.81 & 13 & & 1.78 \\
\hline 4 & & 19.82 & 14 & & 15.38 \\
\hline 5 & & 19.89 & 15 & & 15.34 \\
\hline 6 & \multirow{5}{*}{$\begin{array}{l}\text { Constant temperature } \\
\text { and variable load }\end{array}$} & 18.16 & 16 & & 7.88 \\
\hline 7 & & 17.79 & 17 & & 2.85 \\
\hline 8 & & 17.59 & 18 & & 7.81 \\
\hline 9 & & 17.12 & 19 & & 2.9 \\
\hline 10 & & 16.97 & 20 & & 2.91 \\
\hline
\end{tabular}

\section{CONCLUSION}

(1) The results of the CTVL and VTVL tests showed that the soft soil has large compressibility at normal temperature, and the compressibility coefficient is above $0.913 \mathrm{MPa}^{-1}$, indicating that the studied soil of northeastern in China belongs to the "high compressibility" soil type. The maximum strain of the soil from the CTVL test was $19.89 \%$, and the maximum strain from the VTVL test was $18.16 \%$.

(2) The results of the two kinds of compression tests showed that when the soil temperature is in the severe phase transformation range of $-1.5^{\circ} \mathrm{C}$ to $0^{\circ} \mathrm{C}$, the soil properties are largely changed, and the temperature has a significant influence on the compression characteristics of the soil. 
(3) From the results of the compression tests under VTVL, it was found that the additional compression produced by temperature is the most obvious when the soil temperature is in the temperature range of severe phase transformation $\left(-1.5^{\circ} \mathrm{C}\right.$ to $\left.0^{\circ} \mathrm{C}\right)$. At lower load levels, the additional compression produced by the action of temperature is negligibly small, and at high load levels, the additional compression produced by temperature is relatively large.

\section{AKNOWLEDGMENT}

This work was supported by the Fundamental Research Funds for the Central Universities [2572019BJ02].

\section{REFERENCES}

Bhatt, U. S., Walker, D. A., Raynolds, M. K., et al, 2010. Circumpolar arctic tundra vegetation change is linked to sea ice decline. Earth Interactions. 14(8):1-20.

Cai L.Z, 2015. Study on creep test of sand powder soil with high temperature and ice content in Qinghai-Tibet. Harbin Institute of Technology.

Cheng G.D., Ma W., 2006. Problems of permafrost engineering in Qinghai-Tibet railway construction. Chinese Journal of Nature. 6:315-320.

Harrison, W.D., 1991. Permafrost response to surface temperature change and its implications for the 40,000year surface temperature history at Prudhoe Bay, Alaska. Journal of Geophysical Research Atmospheres. 96(B1): 683-695.

Johannessen, O.M., 1999. Satellite Evidence for an Arctic Sea Ice Cover in Transformation. J.Science. 286(5446):1937-1939.

Liu S.W., Zhang J.M., Zhang H., et al, 2011. Preliminary study on pore water pressure force measurement in high temperature permafrost. Journal of Gansu Agricultural University. 46:155-160.

Ma W., Wang D.Y, 2014. Frozen soil mechanics. Beijing, Science Press.

Oluremi, JR; Adedokun, SI; Yohanna, P.,et al, 2020.Evaluation of compacted laterite soil admixed with cement and hair fibers as road construction material. JOURNAL OF ENGINEERING RESEARCH.8(1):55-71.

Pachauri, R.K.; Reisinger, A., 2007. Climate Change 2007: Synthesis Report. Environmental Policy Collection. 27(2):408.

Phukan A, 1983. Long-term creep deformation of roadway embankment on ice-rich permafrost[C]// Proceedings of the 4th International Conference on Permafrost, National Academy Press.994-999.

Ruan G.F.; Zhang J.M., Liu S.W., et al, 2014. Compression experimental research on warm and ice-rich permafrost on the Qinghai-Tibet Plateau. Hydrogeology \& Engineering Geology. 2:50-56.

Screen, J.A., Simmonds, I.,2010. The central role of diminishing sea ice in recent Arctic temperature amplification. Nature, 464(7293):1334-1337.

Shim, T., Jeong, J.,Kim, B.,Kim, S., et al, 2013. Development of Dynamical Seasonal Prediction System for Northern Winter using the Cryospheric Condition of Late Autumn. Atmosphere. 23(1):73-83.

Shim, T., Jeong, J., Ok, J., Jeong, H., et al, 2015. Development and Assessment of Dynamical Seasonal Forecast System Using the Cryospheric Variables. Atmosphere. 25(1):155-167. 
Su K., Zhang J.M., Liu S.W., et al, 2013. Compressibility of warm and ice-rich frozen soil. Journal of Glaciology and Geocryology. 2:369-375.

Tsytovich, N.A.,1975. The mechanics of frozen ground. Scripta Book Company, Washington, D.C.

Yang Z.H., Still B., Ge X.X., 2015. Mechanical properties of seasonally frozen and permafrost soils at high strain rate. Cold Regions Science and Technology, 113:12-19.

Yao X.L., Qi J.L., Zhang J.M., et al, 2018. A one-dimensional creep model for frozen soils taking temperature as an independent variable. Soils and Foundations. S0038080618300374.

Yu W.X., Yan W.P,1986. Preliminary analysis of freeze-thaw deformation of subgrade in permafrost area of Qinghai-Tibet Highway. Journal of Chang an University(Natural Science Edition). 6:49-70.

Zheng B.; Zhang J.M., Ma X.J., et al, 2009. Study on compression deformation of warm and ice-enriched frozen soil. Chinese Journal of Rock Mechanics and Engineering. (S1):3063-3069.

Zhu Y.L., Zhang J.Y., 1982. Elastic deformation and compression deformation of permafrost. Journal of Glaciology and Geocryology. 3:29-39.

Zimov, S.A., Schuur, E.A.G., Chapin, F.S, 2006. Permafrost and the Global Carbon Budget. Science. 312(5780):1612-1613. 